\section{Cutaneous adverse drug reactions caused by FDCAs - we need to characterise and manage them urgently}

To the Editor: In April 2013, South Africa's Minister of Health launched fixed-dose once-a-day combination antiretrovirals (FDCAs) comprising emtricitabine, efavirenz and tenofovir (Odimune and Tribuss). During the months following the introduction of these drugs, anecdotal reports from clinicians and patients are emerging of cutaneous adverse drug reactions (CADRs) associated with them. We have recently described the clinical characteristics of efavirenz-associated CADRs. ${ }^{[1]}$ Efavirenz is a constituent of the FDCAs, so we have been actively surveying and documenting suspected FDCA-associated CADRs at Groote Schuur Hospital in Cape Town, South Africa.

Between 1 May and 31 August 2013, 7 patients with suspected FDCA-related CADRs presented to Groote Schuur Hospital. We used the Naranjo score, a validated scoring system, to assess the likelihood of the FDCA being the offending drug. The score is based on the pattern of response, the temporal relationship with the drug, withdrawal of the drug, rechallenge with the drug, alternative causes, the placebo response, drug levels in body fluids or tissues, the doseresponse relationship, previous patient experience with the drug, and confirmation by objective evidence. ${ }^{[2]}$ Of the 7 cases, 1 was definitely a CADR associated with the FDCA based on the Naranjo score, 4 were probable cases and 2 were doubtful. The demographic and clinical characteristics of the definite and probable cases are summarised in Table 1. The clinical features were similar to those we described for efavirenz-associated CADRs. ${ }^{[1]}$ All were of moderate severity according to the Common Terminology Criteria for Adverse Events. ${ }^{[3]}$

Because of their ease of use and the consequent improvement in patient compliance, the South African Department of Health expects to initiate $180000 \mathrm{HIV}$-infected people on the FDCAs.
Understanding the side-effect profile so that problems can be managed early on should help clinicians make informed decisions timeously and preserve the reputation of these important drugs in the fight against the HIV pandemic. Large prospective studies are needed urgently to characterise reactions associated with the FDCAs, identify the offending constituent(s) of the combinations, ascertain whether the reactions are severe enough to warrant interruption or termination of therapy, and develop management strategies if the FDCAs are terminated.

\section{Rannakoe J Lehloenya}

\section{Thuraya Isaacs}

Division of Dermatology, Department of Medicine, Faculty of Health Sciences, University of Cape Town, South Africa

rannakoe.lehloenya@uct.ac.za

\section{Sipho Dlamini}

Division of Infectious Disease, Department of Medicine, Faculty of Health Sciences, University of Cape Town, South Africa

\section{Rudzani Muloiwa}

Department of Paediatrics and Child Health, Faculty of Health Sciences,

University of Cape Town, South Africa

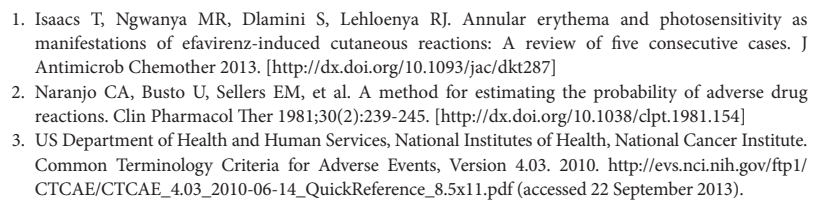

1. Isaacs T, Nowanya MR, Dlamini S, Lehloenya RJ. Annular erythema and photosensitivity as manifestations of efavirenz-induced cutaneous reactions: A review of five consecutive cases. Antimicrob Chemother 2013. [http://dx.doi.org/10.1093/jac/dkt287]

2. Naranjo CA, Busto U, Sellers EM, et al. A method for estimating the probability of adverse drug reactions. Clin Pharmacol Ther 1981;30(2):239-245. [http://dx.doi.org/10.1038/clpt.1981.154]

3. US Department of Health and Human Services, National Institutes of Health, National Cancer Institute. Common Terminology Criteria for Adverse Events, Version 4.03. 2010. http://evs.nci.nih.gov/ftp1/ CTCAE/CTCAE_4.03_2010-06-14_QuickReference_8.5x11.pdf (accessed 22 September 2013).

S Afr Med J 2013;103(11):815. DOI:10.7196/SAMJ.7479

Table 1. Demographic and clinical characteristics of 5 patients with definite or probable cutaneous adverse reactions to fixed-dose once-a-day combination antiretroviral drugs

\begin{tabular}{|c|c|c|c|c|c|c|c|c|c|c|}
\hline Case & $\begin{array}{l}\text { Age } \\
\text { (years) }\end{array}$ & Gender & $\begin{array}{l}\text { Duration of } \\
\text { exposure before } \\
\text { reaction (days) }\end{array}$ & $\begin{array}{l}\text { Tender } \\
\text { palmar } \\
\text { erythema }\end{array}$ & $\begin{array}{l}\text { Annular } \\
\text { erythema }\end{array}$ & $\begin{array}{l}\text { Photo- } \\
\text { distributed }\end{array}$ & Fever & Hepatitis & Eosinophilia & $\begin{array}{l}\text { Naranjo } \\
\text { grade }\end{array}$ \\
\hline 1 & 27 & $\mathrm{~F}$ & 14 & Yes & No & No & Yes & Yes & No & Probable \\
\hline 2 & 38 & M & 11 & Yes & Yes & Yes & Yes & Yes & No & Definite \\
\hline 3 & 39 & $\mathrm{~F}$ & 6 & Yes & Yes & Yes & No & No & No & Probable \\
\hline 4 & 40 & $\mathrm{~F}$ & 31 & Yes & Yes & Yes & No & No & Yes & Probable \\
\hline 5 & 64 & $\mathrm{~F}$ & 2 & Yes & No & No & No & No & No & Probable \\
\hline
\end{tabular}

